\title{
Intrapulmonary autologous transplant of bone marrow-derived mesenchymal stromal cells improves lipopolysaccharide- induced acute respiratory distress syndrome in rabbit
}

Mohammad Reza Mokhber Dezfouli, ${ }^{1,3}$, Massoumeh Jabbari Fakhr ${ }^{3}$, Sirous Sadeghian Chaleshtori ${ }^{1,3^{*}}$, Mohammad Mehdi Dehghan ${ }^{2,3}$, Alireza Vajhi ${ }^{2,3}$ and Roshanak Mokhtari ${ }^{2}$

\begin{abstract}
Background: Lung diseases such as acute respiratory distress syndrome (ARDS) have a high incidence worldwide. The current drug therapies for ARDS have supportive effects, making them inefficient. New methods such as stromal cell therapy are needed for this problem.

Methods: This research was performed with ten New Zealand rabbits in two groups. Bone marrow aspiration was performed on the treated group, and mesenchymal stem cells were isolated and cultured. The experimental model of ARDS was induced using LPS from Escherichia coli strain O55:B5. Then, $10^{10}$ bone marrow mesenchymal stem cells (BM-MSCs) were autologously transplanted intrapulmonary in the treatment group, and 1-2 $\mathrm{ml}$ of PBS in the control group. The clinical signs, computed tomographic (CT) scans, echocardiography, blood gas analysis, complete blood count, and cytokine levels were measured before and at 3, 6, 12, 24, 48, 72, and $168 \mathrm{~h}$ after BM-MSC transplant. Finally, the rabbits were killed, and histopathological examination was performed.

Results: The results showed that BM-MSCs decreased the severity of clinical symptoms, the number of white blood cells and heterophils in the blood, the total cell count, and number of heterophils and macrophages in bronchoalveolar lavage, and balanced the values of arterial blood gases (increase in partial pressure of oxygen and $\mathrm{O}_{2}$ saturation and decrease in the partial pressure of carbon dioxide). They also downregulated the tumor necrosis factor (TNF)- $a$ and interleukin (IL)-6 concentrations and increased the IL-10 concentrations at different times compared with time 0 and in the control group, significantly. In the CT scan, a significant decrease in the Hounsfield units and total lung volume was found by echocardiography, and in comparing the two groups, a significant difference in the parameters was noticed. The histopathology demonstrated that the BM-MSCs were able to reduce the infiltration of inflammatory cells and pulmonary hemorrhage and edema.
\end{abstract}

Conclusions: This study indicated that BM-MSCs play a significant role in the repair of lung injury.

Keywords: ARDS, BM-MSCs, Stromal cell therapy, Intrapulmonary, Rabbit

\footnotetext{
* Correspondence: s.sadeghian@ut.ac.ir

${ }^{1}$ Department of Internal Medicine, Faculty of Veterinary Medicine, University

of Tehran, Tehran, Iran

${ }^{3}$ Institute of Biomedical Research, University of Tehran, Tehran, Iran

Full list of author information is available at the end of the article
}

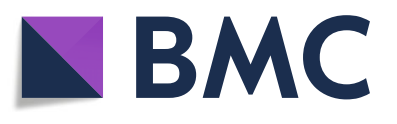

(c) The Author(s). 2018 Open Access This article is distributed under the terms of the Creative Commons Attribution 4.0 International License (http://creativecommons.org/licenses/by/4.0/), which permits unrestricted use, distribution, and reproduction in any medium, provided you give appropriate credit to the original author(s) and the source, provide a link to the Creative Commons license, and indicate if changes were made. The Creative Commons Public Domain Dedication waiver (http://creativecommons.org/publicdomain/zero/1.0/) applies to the data made available in this article, unless otherwise stated. 


\section{Background}

Lung disorders have significant morbidity and mortality rates worldwide, both in humans and in animals. Acute respiratory distress syndrome (ARDS) is one of the leading causes of respiratory failure around the world. Although early diagnosis, timely medical care, and treatment may lead to improvement of symptoms, the signs return after a period of time. Causes of ARDS are different. It can be caused by direct or indirect damage to the lung epithelium. ARDS is described by severe hypoxemia, decreased pulmonary compliance, diffuse alveolar damage, and bilateral pulmonary infiltrates after cardiac edema $[1,2]$ and confirmed by a combination of clinical, physiological, and chest imaging parameters. Pulmonary inflammation with disruption of the mechanism of the alveolar-capillary barrier is an important direct cause of ARDS [3, 4]. Therapeutic approaches include mechanical ventilation, neuromuscular blocking agents, fluid management, drug and antimicrobial therapy, and prone positioning $[3,5,6]$. These therapeutic strategies have a supportive role and cannot prevent the progression of the disease [7-10]. The ultimate approach is lung transplant, but it has many problems for recipient patients such as lack of suitable donors and the use of immunosuppressive drugs over a lifetime to prevent rejection of the transplant [11]. Therefore, the recognition of new therapeutic approaches such as stromal cell therapy is essential [12]. MSCs confer immunomodulatory and anti-inflammatory effects, enhance bacterial clearance, reduce cell injury and death, and are angiogenic $[5,13]$. The mechanism of the MSCs' effects includes several pathways mediated through differentiation, proliferation, soluble intermediate release, extracellular vesicles, transfer of organelles, and direct cell-to-cell contact, which decrease activation of inflammatory cell secretion of paracrine mediators [14, 15]. Recent studies have shown positive effects of MSC-based therapy for ARDS. Induction of inflammation by the LPS of Escherichia coli $\mathrm{O} 55: \mathrm{B} 5$ is one of the best and simplest methods for making an experimental model of ARDS. Although the ARDS animal models cannot reflect human ARDS accurately, the rabbit model is similar and hence suitable for translating the results from pilot to clinical conditions [16]. Anatomical, physiological, genetic, and biochemical similarity to humans simulates human lung disease, and as the rabbit is easy to handle, it is considered as a suitable model for pulmonary research [17, 18]. Moreover, the rabbit serves as an excellent platform for treatment based on stromal cells $[19,20]$. Thus, in this study, the rabbit was used as a model for causing ARDS, and then it was treated with stromal cells. The aim of this study was evaluation of therapeutic potential intrapulmonary administration of BM-MSCs in an experimental model of $E$. coli LPS-induced ARDS in the rabbit.

\section{Methods}

Isolation, primary culture, and expansion of BM-MSCs Bone marrow (BM) samples were obtained from the humerus of rabbits in aseptic surgical conditions. After 30 min of centrifugation (400 relative centrifugal force), mononuclear cells were collected from the interphase, and eventually the cell pellets were seeded into $25-\mathrm{cm}^{2}$ flasks (SPL Life Sciences, Pocheon, South Korea) with DMEM-high glucose, 20\% FBS (Life Technologies, Carlsbad, CA, USA), and $100 \mathrm{U} / \mathrm{ml}$ penicillin/streptomycin (Biowest, Nuaillé, France) and incubated at $37^{\circ} \mathrm{C}$ in humid air with $5 \% \mathrm{CO}_{2}$ (Memmert, Eagle, WI, USA). When the adhesion of the cells was near confluence (more than $70 \%$ ), the cells were trypsinized by trypsinethylenediaminetetraacetic acid of $0.25 \%$ (Life Technologies) and replated at dilutions of 1:2 under conditions of the same cultivation. The characteristics of the BMMSCs were labeled with phycoerythrin-conjugated antibodies against CD45 (BioLegend, San Diego, CA, USA), CD90 (eBioscience, San Diego, CA, USA) and CD34 and CD29 (Abcam, Cambridge, UK), and the multilineage differentiation ability of BM-MSCs to engage in osteogenic and adipogenic differentiation was checked in vitro. This is described in more detail in the additional files.

\section{Experimental design ARDS experimental model}

Ten healthy adult male New Zealand white rabbits were chosen, and an ARDS experimental model was induced with LPS from E. coli O55:B5 [21] (Sigma-Aldrich, St. Louis, MO, USA) at $400 \mu \mathrm{g} / \mathrm{kg}$ dissolved in $0.1 \mathrm{ml}$ of PBS intrapulmonary the under bronchoscopic guidance. After the ARDS confirmation, rabbits were randomly distributed into two groups: (1) the control group (ARDS + PBS) and (2) the treatment group (ARDS + BM-MSC). Protocol details are available in the additional files.

\section{BM-MSC autologous transplant}

A total of $10^{10}$ BM-MSCs suspended in $0.1 \mathrm{ml}$ of PBS [5] were autologously transplanted intrapulmonary under bronchoscopic guidance $24 \mathrm{~h}$ after induction of ARDS. Details of the method are provided in the additional files.

\section{Analyses \\ Clinical assessment}

During the study, the clinical signs of rabbits were calculated and recorded on the basis of clinical scores for each rabbit. Heart rate (HR), respiratory rate (RR), body temperature, twitch, abnormal breathing, nasal discharge, cough, appetite, and physical condition were measured using a clinical score. The scoring is based on clinically evaluated criteria that were individually defined and measured for each rabbit (Additional file 1: Table S1). 


\section{Imaging}

Computed tomography and echocardiography

Computed tomographic (CT) scans of the lung of rabbits were taken with the SOMATOM Spirit Class II (Siemens, Erlangen, Germany), and echocardiographic examinations were performed using a Vivid 7 ultrasound system (GE Healthcare, Milwaukee, WI, USA) with a 4.4-10.0-MHz phased-array transducer (10S) during experimental modeling of ARDS before and 12, 24, 48, 72 , and $168 \mathrm{~h}$ after transplant in each animal under the same circumstances. More details are provided in the additional files.

\section{Sampling}

\section{Blood and bronchoalveolar lavage samples}

Blood samples were collected from the central ear artery for blood gas analyses using blood gas analyzers (OPTI CCA-TS; OPTI Medical Systems, Roswell, GA, USA) and from the ear vein for hematologic parameter analysis and measurement of cytokines (tumor necrosis factor [TNF]- $\alpha$, interleukin [IL]-6, and IL-10) with a commercially available enzyme-linked immunosorbent assay kit (EASTBIOPHARM, Hangzhou, China) before transplant of BM-MSCs and then for 3, 6, 12, 24, 48, 72 , and $168 \mathrm{~h}$ after transplant. Also, bronchoalveolar lavage (BAL) samples were collected by fiberoptic bronchoscope (11262 BC; Karl Storz, Tuttlingen, Germany) before and $24,48,72$, and $168 \mathrm{~h}$ after transplant. Then, the centrifuged BALs were stored at $-80^{\circ} \mathrm{C}$ for measurement of cytokines. Protocol details are available in the additional files.

\section{Histopathology}

The rabbits were killed 7 days after BM-MSC transplant. First, the lungs and hearts were macroscopically examined, and then sections of them were routinely prepared, stained with $\mathrm{H} \& \mathrm{E}$, and observed by use of an E600 Eclipse optical microscope (Nikon Instrument, Tokyo, Japan). More details are provided in the additional files.

\section{Statistical analysis}

The results were analyzed statistically using IBM SPSS Statistics version 24 software (IBM, Armonk, NY, USA). For variables in this study, data were analyzed with the repeated measures independent samples $t$ test, Friedman test, and Mann-Whitney $U$ test, and $p<0.05$ was considered statistically significant.

\section{Results}

\section{Characterization of BMSCs} Culture of BM-MSCs

The plastic adherent BM-MSCs proliferated 5-7 days after seeding and reached $80 \%$ confluence about 2 weeks later. After three passages, the adherent cells were observed by microscopy to display homogeneous spindle fibroblast-like morphology (Additional file 1: Figure S1).

\section{Flow cytometric analysis}

Flow cytometric analysis demonstrated that cultured BM-MSCs expressed a particular pattern of cell surface markers of CD29 and CD90, 92\% and 89\%, respectively, but were uniformly negative for CD34 and CD45 (Additional file 1: Figure S2), which indicates cultured adherent cells were MSCs with high purity. Thus, the pure MSCs whose immunophenotype was confirmed were used in this study.

\section{Differentiation}

Multilineage differentiation ability of BM-MSCs to engage in osteogenic and adipogenic differentiation in vitro confirmed potential pluripotent MSCs, and their ability to form osteoblasts and adipocytes when incubated in differentiation medium was retained (Additional file 1: Figure S3).

\section{Confirmation of ARDS experimental model}

Twenty-four hours after the intrapulmonary administration of LPS, inflammation and edema were stabilized in the lung. Two different evaluations proved ARDS occurrence: (1) Clinical examination showed changes in respiratory sounds during auscultation, such as crackle and wheeze, increased respiratory rate/hyperpnea $(p=0.004)$, heart rate/ tachycardia $(p=0.008)$ and body temperature/hyperthermia $(p=0.011)$, cough, mucus hyperemia, abnormal discharge, and reduced appetite; and (2) plain chest radiograph showing significant bilateral radiologic density (air bronchogram and air alveologram patterns and lung edema and bronchial and bronchiolar septum thickness) were also confirmed (Additional file 1: Figure S4). These results confirmed the experimental model of ARDS compared with the baseline $24 \mathrm{~h}$ after injection of LPS.

\section{Clinical and paraclinical findings after transplant of BM- MSCs in an experimental model of ARDS Improved clinical signs with MSCs}

According to the statistical analysis, reduction of $R R$ in the treatment group was significant at $24 \mathrm{~h}(p=0.002)$, $48 \mathrm{~h}(p=0.036), 72 \mathrm{~h}(p=0.037)$, and $168 \mathrm{~h}(p=0.042)$ after BM-MSC transplant compared with time 0 (before BM-MSC transplant). HR reduction was significant at $24 \mathrm{~h}(p=0.047)$ after transplant compared with time 0 , but in $\mathrm{RR}$ and $\mathrm{HR}$ in the control group, it was not significantly different at various times. The RR results of the comparison between two groups showed a significant difference at $24 \mathrm{~h}(p=0.028), 48 \mathrm{~h}(p=0.03), 72 \mathrm{~h}$ $(p=0.01)$, and $168 \mathrm{~h}(p=0.044)$ (Fig. 1 and Additional 


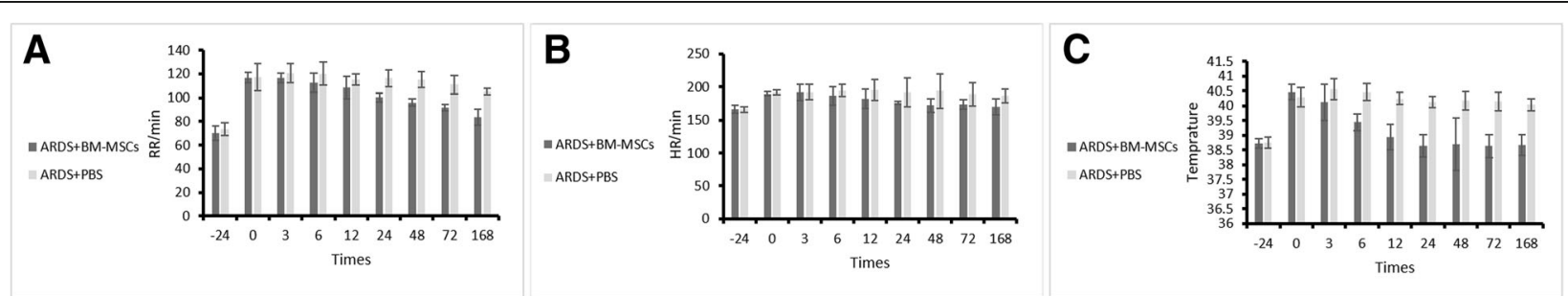

Fig. 1 Vital signs of rabbits (mean \pm SD) in the treatment (acute respiratory distress syndrome [ARDS] + bone marrow mesenchymal stem cells) and control (ARDS + PBS) groups at the different time points. a Respiratory rate. b Heart rate. $\mathbf{c}$ Body temperature

file 1: Table S2). The body temperature change in rabbits of the treatment group was significant at $6 \mathrm{~h}(p=0.010)$, $12 \mathrm{~h}(p=0.016), 24 \mathrm{~h}(p=0.044), 72 \mathrm{~h}(p=0.044)$, and 168 $\mathrm{h}(p=0.043)$ after transplant compared with time 0 . Also, the comparison between two groups showed significant differences at $12 \mathrm{~h}(p=0.047), 24 \mathrm{~h}(p=0.021), 48$ $\mathrm{h}(p=0.035)$, and $168 \mathrm{~h}(p=0.037)$ (Fig. 1 and Additional file 1: Table S2).

Changes in respiratory sounds (including crackle, wheeze, friction sounds) in the treatment group were significant compared with the control group at $24 \mathrm{~h}(p=0.50), 48$ h $(p=0.014), 72 \mathrm{~h}(p=0.017)$, and $168 \mathrm{~h}(p=0.014)$ after transplant. Comparison of appetite between the two groups displayed a positive and significant association at $12 \mathrm{~h}(p=0.002), 24 \mathrm{~h}(p=0.014), 48 \mathrm{~h}(p=0.007), 72 \mathrm{~h}$ $(p=0.004)$, and $168 \mathrm{~h}(p=0.004)$ after transplant.

In both groups, after inflammation, unilateral or bilateral mucosal secretions from the nose were produced that were occasionally accompanied by color changes. But after transplant of BM-MSCs, statistical comparison showed a significant decrease in nasal discharge compared with the control group at $24 \mathrm{~h}(p=0.011), 48$ h $(p=0.007), 72 \mathrm{~h}(p=0.007)$, and $168 \mathrm{~h}(p=0.008)$. The regular rhythm of nasal twitching in the rabbit is a reason for the rabbit's health and alertness. Nasal twitching was reduced at the time of inflammation. But there was a significant difference between results at 12 $\mathrm{h}(p=0.005), 24 \mathrm{~h}(p=0.005), 72 \mathrm{~h}(p=0.014)$, and 168 h $(p=0.014)$ after transplant.

Also, there was a significant decrease in cough count between the two groups at $12 \mathrm{~h}(p=0.014), 24$ h $(p=0.005), 48 \mathrm{~h}(p=0.006), 72 \mathrm{~h}(p=0.004)$, and $168 \mathrm{~h}(p=0.005)$. Regarding the statistical analysis, comparison of mucous membranes (conjunctiva, palpebra tertia, gingiva, rectum) in both groups showed hyperemia reduced at $24 \mathrm{~h}(p=0.031), 48 \mathrm{~h}(p=$ $0.011), 72 \mathrm{~h}(p=0.005)$, and $168 \mathrm{~h}(p=0.005)$ after BM-MSC transplant. After inflammation, rabbits showed depression and delay in response to environmental stimuli. But transplant of BM-MSCs indicated a significant improvement in consciousness at $24 \mathrm{~h}(p=0.017), 48 \mathrm{~h}$ $(p=0.017), 72 \mathrm{~h}(p=0.004)$, and $168 \mathrm{~h}(p=0.005)$.

\section{MSCs cause blood cells and BAL cells to balance Blood cells}

The measured blood parameters at different times are shown in the Table 1. Rabbits in the two groups had significant leukocytosis 1 day after inflammation $(p<0.005)$. But the BM-MSC transplant reduced the number of white blood cells. The changes were significant at 12 h $(p=0.046), 24 \mathrm{~h}(p=0.019), 48 \mathrm{~h}(p=0.022), 72 \mathrm{~h}$ $(p=0.044)$, and $168 \mathrm{~h}(p=0.043)$ compared with time 0 . Also, comparison of the two groups showed that cell transplant was effective at $6 \mathrm{~h}(p=0.043), 12 \mathrm{~h}(p=0.000)$, and $24 \mathrm{~h}(p=0.047)$ (Table 1).

The transplant of BM-MSCs reduced the heterophil count following ARDS. Changes were significant at 12 $\mathrm{h}(p=0.048), 24 \mathrm{~h}(p=0.049), 48 \mathrm{~h}(p=0.009), 72 \mathrm{~h}$ $(p=0.007)$, and $168 \mathrm{~h}(p=0.024)$ against inflammation time (time 0 ). The comparison between two groups showed significant differences at $3 \mathrm{~h}(p=0.020), 6 \mathrm{~h}$ $(p=0.042), 12 \mathrm{~h}(p=0.030), 24 \mathrm{~h}(p=0.001)$, and $48 \mathrm{~h}$ $(p=0.046)$ (Additional file 1: Figure S5).

Comparison of heterophil band numbers between the two groups showed that cell transplant was affected at $48 \mathrm{~h}(p=0.046), 72 \mathrm{~h}(p=0.021)$, and $168 \mathrm{~h}(p=0.038)$.

Statistical analysis showed that there was no significant difference in the lymphocyte count, monocytes, platelets, hematocrit in or between the treatment and control groups during the study. There was a significant difference in the number of red blood cells $(p=0.007)$ and concentration of hemoglobin $(p=0.027)$ in the treatment group compared with the control group only at $48 \mathrm{~h}$.

\section{Cells from $B A L$}

In BAL, the total nucleated cell count included ciliated epithelial cells, squamous epithelial cells, alveolar macrophages, leukocytes, heterophils, eosinophils, and plasma cells. Typically, total leukocyte cells in treatment group included macrophages and lymphocytes, and in the control group, they included macrophages and heterophils (Fig. 2).

The results demonstrated that the BAL cell count was significantly increased in inflammatory conditions, but 


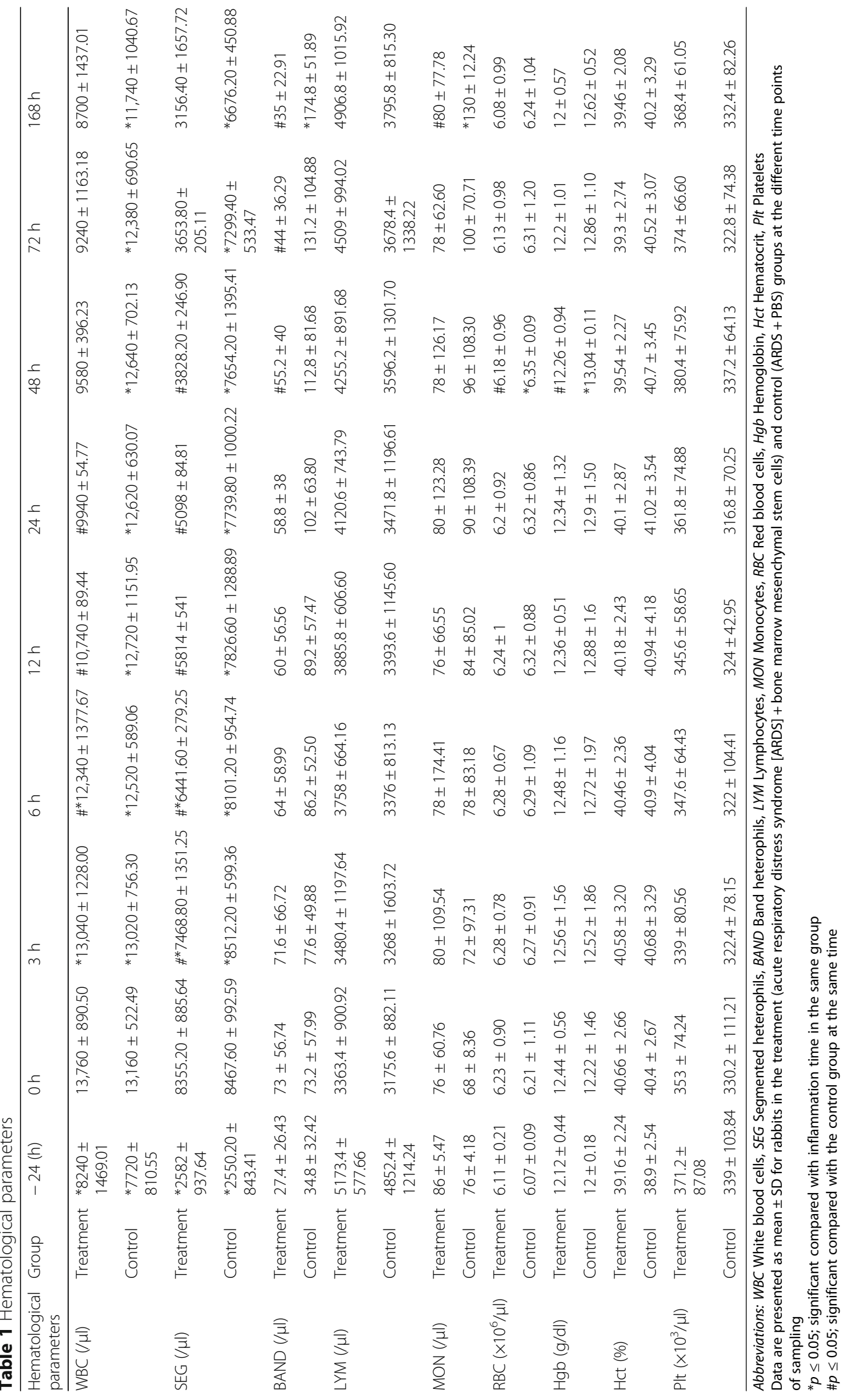




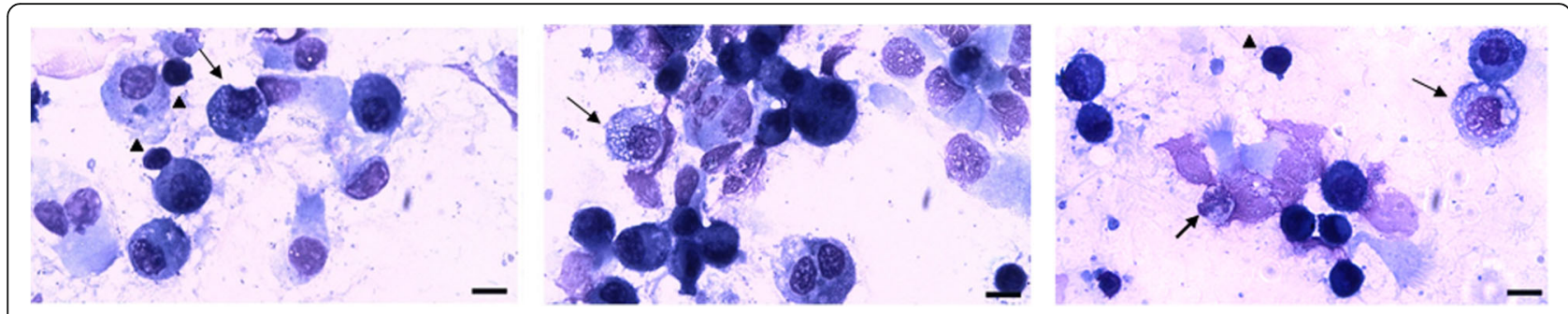

Fig. 2 Determination of complete cell counts in bronchoalveolar lavage (BAL) samples of the rabbit. Using Wright-Giemsa staining, we counted inflammatory cells in the BAL samples of the control group among the total of 100 cells. Macrophages (arrow), heterophils (thick arrow), lymphocyte (arrowhead). Bars $=50 \mu \mathrm{m}$

transplant of stromal cells caused the inflammatory cells to balance so that, in the treatment group, decrease of the total cell count was significant at all times except time $0(p<0.05)$, and there was a significant reduction in the total cell count compared with the control group at $24 \mathrm{~h}(p=0.045), 48 \mathrm{~h}(p=0.46)$, and $72 \mathrm{~h}(p=0.048)$. Also, BM-MSCs were able to significantly reduce the number of alveolar heterotrophs, as well as the number of macrophages in BAL, so that decrease of heterotrophs was significant at $12 \mathrm{~h}(p=0.03), 24 \mathrm{~h}(p=0.01), 48 \mathrm{~h}, 72$ $\mathrm{h}$, and $168 \mathrm{~h}(p=0.000)$ against inflammation time and at $48 \mathrm{~h}(p=0.049), 72 \mathrm{~h}(p=0.031)$, and $168 \mathrm{~h}(p=0.042)$ compared with the control group. Also, reduction in macrophages was significant at $72 \mathrm{~h}(p=0.033)$ and $168 \mathrm{~h}(p=0.005)$ compared with time 0 . No significant change in the number of lymphocytes was observed in or between the two groups (Fig. 3) (Additional file 1: Table S3).

\section{Regulation of arterial blood gases with MSCs}

The partial pressure of oxygen $\left(\mathrm{PO}_{2}\right)$ and $\mathrm{O}_{2}$ saturation $\left(\mathrm{SatO}_{2}\right)$ levels were decreased, and partial pressure of carbon dioxide $\left(\mathrm{PCO}_{2}\right)$ levels were increased, in ARDS (time 0) compared with baseline $(-24 \mathrm{~h})$, significantly. Following $\mathrm{BM}-\mathrm{MSC}$ transplant, $\mathrm{PO}_{2}$ increment was significant at $12 \mathrm{~h}(p=0.043), 24 \mathrm{~h}(p=0.005)$, and $48 \mathrm{~h}$ $(p=0.005)$, and comparison between the two groups demonstrated that severe hypoxemia was significantly recovered after transplant at $12 \mathrm{~h}(p=0.027), 24 \mathrm{~h}(p=$ $0.042)$, and $48 \mathrm{~h}(p=0.040)$.

Also, following transplant of BM-MSCs, changes of $\mathrm{SatO}_{2}$ were significant at $12 \mathrm{~h}(p=0.038), 24 \mathrm{~h}(p=0.030)$, $48 \mathrm{~h}(p=0.009), 72 \mathrm{~h}(p=0.007)$, and $168 \mathrm{~h}(p=0.024)$ compared with time 0 , and comparison of the two groups showed that cell transplant was effective at $3 \mathrm{~h}(p=0.020)$, $6 \mathrm{~h}(p=0.042), 12 \mathrm{~h}(p=0.030), 24 \mathrm{~h}(p=0.001)$, and $48 \mathrm{~h}$ $(p=0.046)$ (Additional file 1: Table S4).

Additionally, $\mathrm{PCO}_{2}$ was significantly decreased in the treatment group at $24 \mathrm{~h}(p=0.036), 48 \mathrm{~h}(p=0.034)$, and $72 \mathrm{~h}(p=0.01)$ after transplant, and comparison between the two groups displayed a significant decrease of $\mathrm{PCO}_{2}$ at $48 \mathrm{~h}$ and $72 \mathrm{~h}(p=0.016)$.

Also, statistical analysis for $\mathrm{pH}$ value indicated significant differences between the two groups at $24 \mathrm{~h}(p=0.019)$. Respiratory acidosis occurred in both groups at 3 and $6 \mathrm{~h}$ via $\mathrm{pH}$ decrease and increase in $\mathrm{PCO}_{2}$. Analysis of bicarbonate, base excess, and anion gap data showed no significant difference in and between the two groups (Fig. 4).

\section{Effect of MSCs on arterial blood electrolytes}

The results showed nonsignificant reduction in the value of $\mathrm{Na}^{+}, \mathrm{K}^{+}$, and $\mathrm{Cl}^{-}$in and between the treatment and control groups at the different times and alone. There was a significant difference in the $\mathrm{Cl}^{-}$value in the treatment group compared with the control group at $24 \mathrm{~h}(p=0.029)$ (Additional file 1: Table S5).

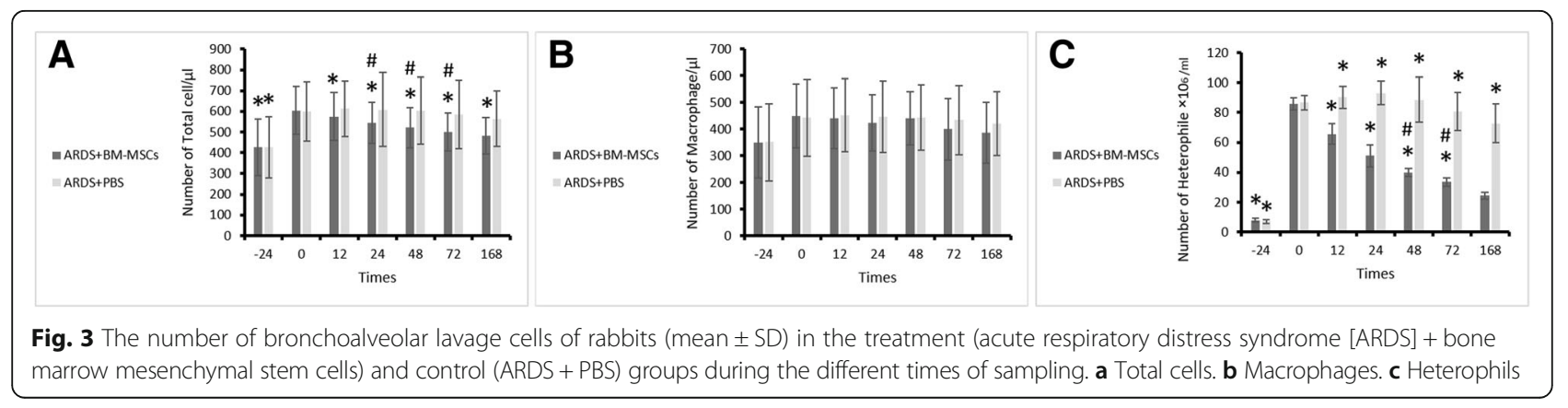




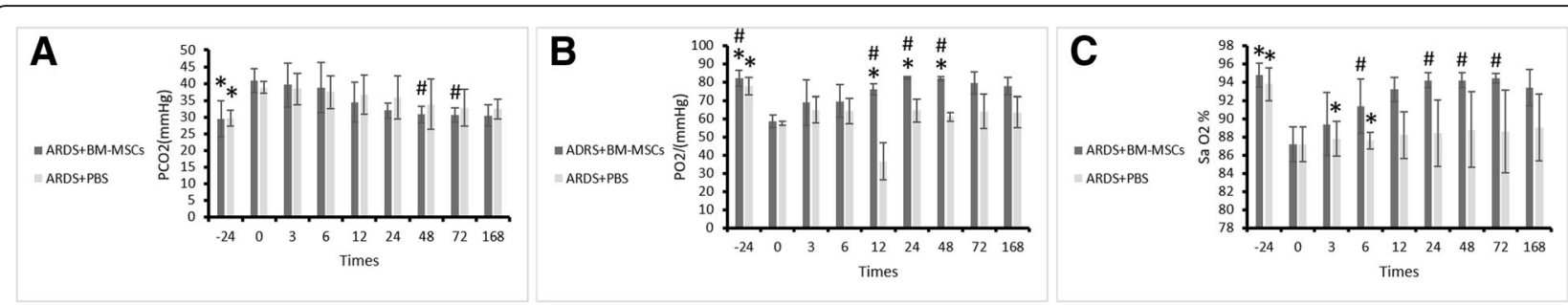

Fig. 4 Arterial blood gas analysis of rabbits $(m e a n \pm S D$ ) in the treatment (acute respiratory distress syndrome [ARDS] + bone marrow mesenchymal stem cells) and control (ARDS + PBS) groups during the different times of sampling. a Partial pressure of carbon dioxide. b Partial pressure of oxygen. $\mathrm{C}_{2}$ saturation

\section{Reduced levels of proinflammatory cytokines and increase in anti-inflammatory cytokine by MSCs}

Duplicated measurements of each variable were performed, and the average of the data was obtained. The measured cytokine levels in plasma and BAL samples at different times are shown in Additional file 1: Table S6. BM-MSC transplant decreased proinflammatory cytokines (TNF- $\alpha$ and IL-6) and increased anticytokine inflammation (IL-10) during endotoxin injury in plasma and BAL.

After transplant of MSCs, the concentration of the TNF- $\alpha$ in BAL decreased at $12 \mathrm{~h}(p=0.035), 24 \mathrm{~h}(p=0.011), 48 \mathrm{~h}$ $(p=0.007)$, and $168 \mathrm{~h}(p=0.014)$ compared with time 0 , significantly, and comparison of the two groups showed that cell transplant was affected at times of 12 h $(p=0.031), 24 \mathrm{~h}(p=0.018), 48 \mathrm{~h}(p=0.009)$, and $168 \mathrm{~h}(p=0.014)$. Also, the levels of TNF- $\alpha$ in plasma were recovered with MSCs at $24 \mathrm{~h}(p=0.040), 48 \mathrm{~h}(p=0.006)$, $72 \mathrm{~h}(p=0.002)$, and $168 \mathrm{~h}(p=0.003)$ against inflammation time $(0 \mathrm{~h})$, significantly, and comparison of the two groups showed significant difference at $72 \mathrm{~h}(p=0.008)$ and $168 \mathrm{~h}(p=0.025)$.

The IL- 6 concentration was downregulated by MSCs, so that the levels of IL-6 in the BAL were significantly lower at times of $12 \mathrm{~h}(p=0.047), 24 \mathrm{~h}(p=0.011), 48 \mathrm{~h}$ $(p=0.001)$, and $168 \mathrm{~h}(p=0.041)$ than time 0 . Comparison of the two groups indicated significant differences at $12 \mathrm{~h}(p=0.032), 24 \mathrm{~h}(p=0.018), 72 \mathrm{~h}(p=0.041)$, and $168 \mathrm{~h}(p=0.008)$. Also, the concentration of IL-6 was significant in plasma $48 \mathrm{~h}(p=0.048)$ and $168 \mathrm{~h}(p=0.001)$ after MSC transplant against the inflammation time $(0 \mathrm{~h})$, and comparison of the two groups showed that cell therapy was affected at $24 \mathrm{~h}(p=0.001), 48 \mathrm{~h}(p=0.005)$, and $168 \mathrm{~h}(p=0.012)$. These results demonstrated the immunomodulatory potential of these BM-MSCs.

In contrast, when MSCs were administered, IL-10 was significantly increased in the BAL and plasma. Concentration of IL-10 in BAL was significant at $12 \mathrm{~h}$ $(p=0.047), 24 \mathrm{~h}(p=0.011), 48 \mathrm{~h}(p=0.001)$, and $168 \mathrm{~h}$ $(p=0.041)$ compared with time 0 , and comparison of the two groups showed significant differences at $12 \mathrm{~h}$ $(p=0.032), 24 \mathrm{~h}(p=0.018), 72 \mathrm{~h}(p=0.041)$, and $168 \mathrm{~h}$ $(p=0.008)$ (Fig. 5). Also, increase of IL-10 concentration in plasma was significant at $48 \mathrm{~h}(p=0.047), 72 \mathrm{~h}$ $(p=0.044)$, and $168 \mathrm{~h}(p=0.022)$ against time 0 . MSCs also increased plasma IL-10 concentrations compared with control group at $48 \mathrm{~h}(p=0.043)$ and $72 \mathrm{~h}(p=0.029)$, significantly (Fig. 5), so that BMSCs reduced lung injury and inflammation via significant immunomodulatory properties and attenuated the severity of ARDS.

\section{Imaging findings \\ Tomodensitometric and volumetric findings of lung CT scans}

Hounsfield units and volumes of the aerated and nonaerated areas of the right and left lungs were measured on CT scans. Quantitative estimation (the Hounsfield unit measurement) was done for different adjacent CT sections with the Leonardo workstation and software tools (Siemens). Lung parenchymal margins were manually demarcated, and then average Hounsfield units were obtained for each section. Also, the 3D pattern was observed for a better evaluation of the lung parenchyma (data not shown). These measurements demonstrated that Hounsfield units had increased 1 day after the experimental inflammation (before stromal cells therapy), which represents replacement of alveolar air with mucous and inflammatory cells (Fig. 6). A significant decrease in the Hounsfield units was seen at $48 \mathrm{~h}(p=0.032), 72 \mathrm{~h}$ $(p=0.036)$, and $168 \mathrm{~h}(p=0.025)$ post-transplant, which indicates an increase in aerated volume of the lung in the treatment group. Also, variation volumes were compared and showed that total lung volume (aerated + nonaerated + tissue + edematous fluids) in both groups increased after ARDS, but transplant of BM-MSCs had decreased the process at $72 \mathrm{~h}(p=0.047)$ and $168 \mathrm{~h}(p=0.027)$. On CT scans, most nonaerated areas were observed in lower lobes in the caudoventral area (Fig. 7 and Additional file 1: Table S7).

\section{Echocardiography findings}

The images and amounts of Doppler and M-mode echocardiographic parameters are shown in Additional file 1: Figure S6. The amounts of BAL and plasma cytokines of 


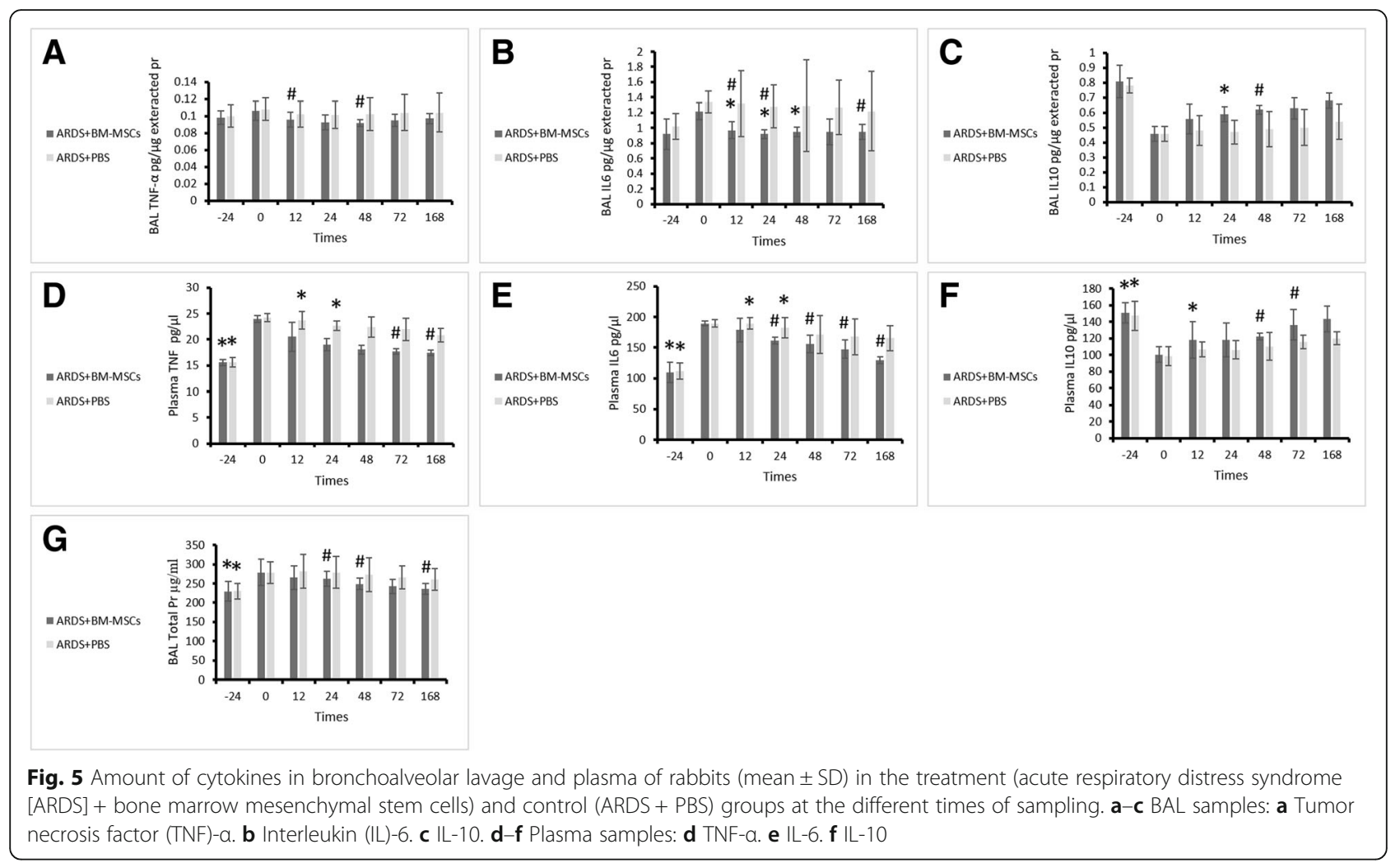

rabbits are shown in Fig. 6 and Table 2, respectively. Echocardiographic data showed no significant difference in the treatment group (BM-MSC recipients), but comparison of the two groups revealed that percentage ejection fraction at $72 \mathrm{~h}(p=0.042)$ and $168 \mathrm{~h}(p=0.038)$, percentage fractional shortening at $72 \mathrm{~h}(p=0.049)$ and $168 \mathrm{~h}(p=0.044)$, interventricular septal end diastole at $48 \mathrm{~h}(p=0.014), 72 \mathrm{~h}(p=0.038)$, and $168 \mathrm{~h}(p=0.042)$, interventricular septal end systole at $24 \mathrm{~h}(p=0.005)$, $48 \mathrm{~h}(p=0.009)$, and $72 \mathrm{~h}(p=0.010)$, left ventricular internal dimension systole at $72 \mathrm{~h}(p=0.048)$ and $168 \mathrm{~h}$ $(p=0.022)$, aortic root diameter at $72 \mathrm{~h}(p=0.027)$ and $168 \mathrm{~h}(p=0.042)$, left atrial diameter at $168 \mathrm{~h}(p=0.048)$, left ventricular outflow tract maximum velocity at $168 \mathrm{~h}$ $(p=0.041)$ and right ventricular outflow tract maximum velocity at $168 \mathrm{~h}(p=0.039)$ had significant differences.

\section{Findings of gross pathology and histopathology}

The macroscopic examination of the lungs showed hyperemia, hemorrhage, emphysema, edema, and hepatization in the control group (Fig. 8a), but brief hyperemia and edema were observed in the treatment
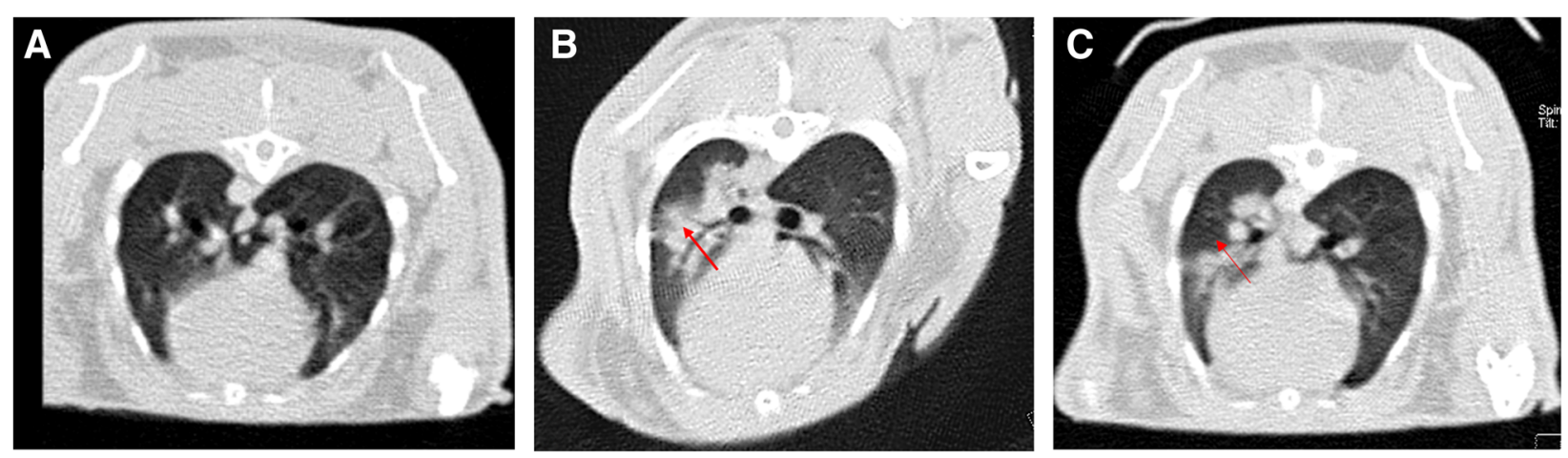

Fig. 6 High-resolution computed tomographic scans of the thorax (lung window) in the rabbit. a Transverse section of lung. b Increased attenuation due to inflammation in the lung of the control group. Notice the typical air bronchogram (alveolar lung pattern). c Decreased attenuation in the lung of the treatment group (recipient of bone marrow mesenchymal stem cells). The dorsal regions of the lung have the highest volume 


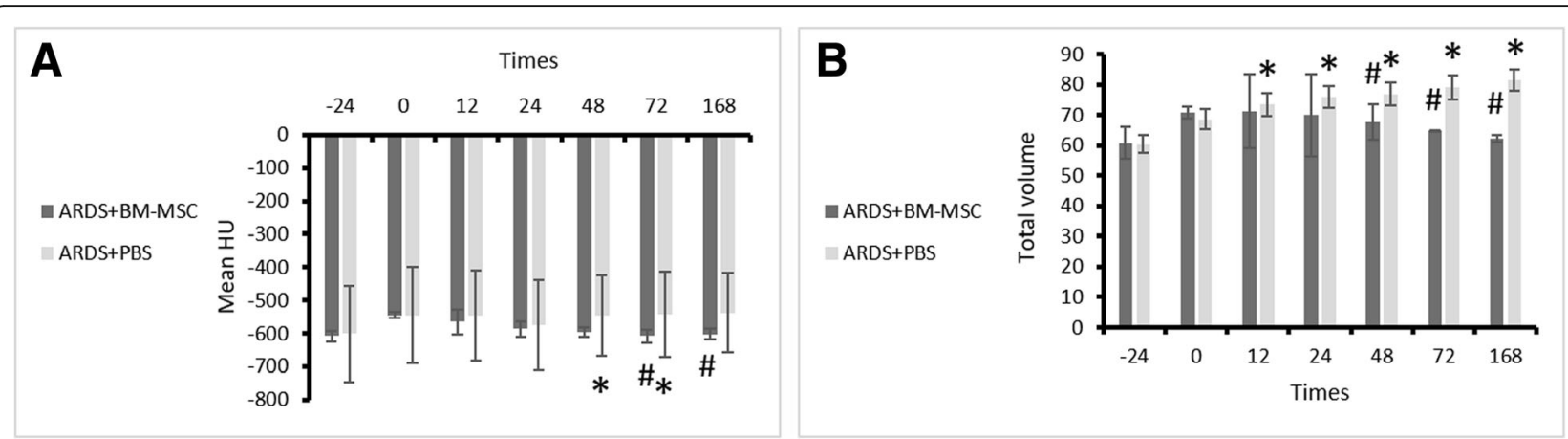

Fig. 7 The amount of computed tomographic scan volumetry (mean Hounsfield units and total volume) of rabbits (mean \pm SD) in the treatment (acute respiratory distress syndrome [ARDS] + bone marrow mesenchymal stem cells) and control (ARDS+PBS) groups at the different time points. a Mean Hounsfield units. b Total volume

group (Fig. 8f). Sections of the lung demonstrated different histopathological patterns between the control and treatment groups. Microscopically, lungs showed more severe damage in the control group than the treatment group as hemorrhage in parenchyma and alveoli, moderate to severe vascular hyperemia, moderate to severe interstitial pneumonia, severe alveolar injuries and edema, neutrophilic margination in the capillary vessels, abundant presence of inflammatory cells, epithelial cells and other cell debris (cellularity) in interstitial spaces and alveoli, and thickness of the alveolar septum (Fig. 8b-d). But treatment with BM-MSCs reduced the infiltration rate of inflammatory cells in the alveolar septum, hyperemia, hemorrhage, and edema, and lung structure was approximately normal and only slightly increased the thickness of the alveolar septum. Also, in most sections of the treatment group, injury in the bronchus, bronchioles, and vessels was not observed (Fig. 8g-i).

In macroscopic observations of the heart, no lesions were found in both treatment and control groups, but in the microscopic examination of the heart sections in the control group, necroses were observed in a small number of myofibers (Fig. 8e), whereas in treatment group, no injury was observed (Fig. 8k).

\section{Discussion}

BM-MSCs are an ideal choice for cell therapy because there are fewer complications for cell isolation and also $\mathrm{BM}$ autologous cells that are capable of eliminating immune response and transplant rejection [22]. MSCs have positive effects in the repair of ARDS [23].

Although fibroblasts play a role in normal and pathological repair, and an accumulation of fibrocytes, fibroblasts, and myofibroblasts in the alveolar compartment, leading to excessive deposition components of the extracellular matrix but also according to prior findings the effect of them remains controversial [2325] and unknown, so that reduction of its deposition or enhancement of its degradation could be treatment strategies. [24]

The results of this study showed that the BM-MSCs significantly decreased the severity of clinical symptoms induced by LPS, the number of inflammatory cells in blood and BAL, and balanced the values of arterial blood gases and cytokines. On the CT scans, a significant decrease in the Hounsfield units was observed, which is indicative of an increase in aerated volume of the lung in the treatment group. The echocardiographic parameters did not reveal a significant difference in the treatment group, and compared with the two groups together it was significant. Also, the histopathology demonstrated reduction in the infiltration of inflammatory cells and pulmonary hemorrhage and edema in the recipients of BM-MSCs.

In natural conditions, cells from bone marrow migrated to chemotactic gradients, but the amount of engraftment was low, and use of exogenous stromal cells can be helpful to this mechanism. The exact mechanisms of MSCs' actions are not precise [25], and sometimes the results of stromal cell research using animal models are incompatible with each other [23]. However, three mechanisms have been defined for MSCs' actions consisting of differentiation, cell-cell contact and paracrine function via the soluble factors $[25,26]$. Researchers are likely to focus on manipulation of inflammatory pathways and optimizing lung repair while preventing ARDS progression [6]; whereas management of inflammatory pathways forbids the development of ARDS, some researchers believe in the immunomodulatory effects of MSCs [6]. Most trials have used local delivery of autologous BM-MSCs with the aim increasing the concentration of growth factors and cytokines in damaged tissue to improve possible engraftment and repair [23]. For the first time, Gupta et al. reported effects of the local delivery of MSCs in ARDS that are consistent with this study [26]. 
Table 2 M-mode and Doppler echocardiography parameters

\begin{tabular}{|c|c|c|c|c|c|c|c|c|}
\hline Time (h) & Group & $-24 h$ & $\mathrm{Oh}$ & $12 \mathrm{~h}$ & $24 \mathrm{~h}$ & $48 \mathrm{~h}$ & $72 \mathrm{~h}$ & $168 \mathrm{~h}$ \\
\hline \multicolumn{9}{|l|}{ Parameters } \\
\hline \multirow[t]{2}{*}{$\mathrm{EDV}(\mathrm{mm})$} & Treatment & $2.5 \pm 0.82$ & $3.01 \pm 0.86$ & $3.76 \pm 1.68$ & $4 \pm 1.09$ & $3.87 \pm 0.88$ & $3.42 \pm 0.97$ & $3.24 \pm 0.29$ \\
\hline & Control & $2.65 \pm 1.11$ & $3.49 \pm 0.72$ & $3.92 \pm 1.52$ & $3.38 \pm 0.79$ & $2.95 \pm 0.67$ & $3.02 \pm 0.75$ & $3.13 \pm 0.73$ \\
\hline \multirow[t]{2}{*}{ EF (\%) } & Treatment & $57.6 \pm 9.3$ & $63.1 \pm 6.6$ & $68.96 \pm 15.5$ & $60.95 \pm 9.5$ & $57.45 \pm 12.92$ & $63.03 \pm 7.72$ & $61.38 \pm 3.7$ \\
\hline & Control & $56.33 \pm 6.6$ & $62.99 \pm 5.6$ & $65.02 \pm 14.86$ & $67.52 \pm 17.68$ & $59.88 \pm 12.24$ & $\# 55.03 \pm 20.01$ & $\# 51.1 \pm 18.4$ \\
\hline \multirow[t]{2}{*}{ ESV (mm) } & Treatment & $0.89 \pm 0.25$ & $1.13 \pm 0.53$ & $1.22 \pm 1.24$ & $1.09 \pm 0.74$ & $1 \pm 0.25$ & $1.06 \pm 0.46$ & $1.05 \pm 0.49$ \\
\hline & Control & $0.93 \pm 0.79$ & $1.25 \pm 0.46$ & $1.3 \pm 0.27$ & $1.15 \pm 0.69$ & $1.06 \pm 0.49$ & $1.04 \pm 0.4$ & $1.02 \pm 0.3$ \\
\hline \multirow[t]{2}{*}{ FS (\%) } & Treatment & $33.72 \pm 10.58$ & $36.92 \pm 8.26$ & $35.01 \pm 12.47$ & $37.09 \pm 13.47$ & $35.24 \pm 7.24$ & $34.81 \pm 6.12$ & $34.91 \pm 4.11$ \\
\hline & Control & $35.1 \pm 12.74$ & $38.58 \pm 9.5$ & $37.5 \pm 5.78$ & $36 \pm 3.39$ & $33.8 \pm 10.41$ & $\# 31.01 \pm 15.03$ & \#28.41 \pm 16.22 \\
\hline \multirow[t]{2}{*}{ IVSd (mm) } & Treatment & $0.25 \pm 0.06$ & $0.27 \pm 0.047$ & $0.27 \pm 0.027$ & $0.26 \pm 0.065$ & $0.25 \pm 0.037$ & $0.26 \pm 0.045$ & $0.25 \pm 0.08$ \\
\hline & Control & $0.37 \pm 0.13$ & $0.38 \pm 0.083$ & $0.37 \pm 0.073$ & $0.41 \pm 0.1$ & $\# 0.34 \pm 0.17$ & $\# 0.35 \pm 0.12$ & $\# 0.35 \pm 0.22$ \\
\hline \multirow[t]{2}{*}{ IVSs (mm) } & Treatment & $0.37 \pm 0.19$ & $0.39 \pm 0.07$ & $0.4 \pm 0.04$ & $0.35 \pm 0.04$ & $0.36 \pm 0.06$ & $0.34 \pm 0.08$ & $0.33 \pm 0.12$ \\
\hline & Control & $0.51 \pm 0.13$ & $0.59 \pm 0.18$ & $0.59 \pm 0.23$ & $0.66 \pm 0.3$ & $\# 0.57 \pm 0.35$ & $\# 0.55 \pm 0.34$ & $\# 0.57 \pm 0.3$ \\
\hline \multirow[t]{2}{*}{ LVIDd (mm) } & Treatment & $0.99 \pm 0.09$ & $1.11 \pm 0.12$ & $1.18 \pm 0.23$ & $1.25 \pm 0.11$ & $1.26 \pm 0.11$ & $1.29 \pm 0.24$ & $1.16 \pm 0.02$ \\
\hline & Control & $1 \pm 0.18$ & $1.19 \pm 0.09$ & $1.37 \pm 0.31$ & $1.19 \pm 0.11$ & $1.13 \pm 0.09$ & $\# 1.17 \pm 0.14$ & $\# 1.18 \pm 0.12$ \\
\hline \multirow[t]{2}{*}{ LVIDs (mm) } & Treatment & $0.55 \pm 0.1$ & $0.77 \pm 0.13$ & $0.87 \pm 0.36$ & $0.74 \pm 0.25$ & $0.64 \pm 0.06$ & $0.66 \pm 0.04$ & $0.6 \pm 0.05$ \\
\hline & Control & $0.57 \pm 0.28$ & $0.88 \pm 0.14$ & $0.88 \pm 0.28$ & $0.79 \pm 0.22$ & $0.76 \pm 0.13$ & $0.75 \pm 0.18$ & $0.73 \pm 0.57$ \\
\hline \multirow[t]{2}{*}{ LVPWd } & Treatment & $0.39 \pm 0.06$ & $0.31 \pm 0.09$ & $0.29 \pm 0.04$ & $0.28 \pm 0.05$ & $0.28 \pm 0.03$ & $0.31 \pm 0.06$ & $0.3 \pm 0.08$ \\
\hline & Control & $0.31 \pm 0.1$ & $0.33 \pm 0.061$ & $0.29 \pm 0.06$ & $0.35 \pm 0.08$ & $0.38 \pm 0.08$ & $0.36 \pm 0.08$ & $0.34 \pm 0.08$ \\
\hline \multirow[t]{2}{*}{ LVPWs } & Treatment & $0.48 \pm 0.1$ & $0.46 \pm 0.09$ & $0.39 \pm 0.1$ & $0.47 \pm 0.14$ & $0.43 \pm 0.14$ & $0.48 \pm 0.16$ & $0.41 \pm 0.7$ \\
\hline & Control & $0.42 \pm 0.1$ & $0.44 \pm 0.16$ & $0.46 \pm 0.09$ & $0.46 \pm 0.09$ & $0.57 \pm 0.1$ & $0.56 \pm 0.13$ & $0.54 \pm 0.17$ \\
\hline \multirow[t]{2}{*}{ SV (ml) } & Treatment & $1.71 \pm 0.41$ & $1.87 \pm 0.48$ & $2.1 \pm 0.74$ & $2.76 \pm 0.36$ & $2.44 \pm 0.62$ & $2.36 \pm 0.82$ & $2.19 \pm 0.79$ \\
\hline & Control & $2.16 \pm 0.61$ & $2.23 \pm 0.44$ & $2.61 \pm 1.47$ & $2.22 \pm 0.22$ & $1.89 \pm 0.56$ & $1.98 \pm 0.38$ & $2.01 \pm 0.6$ \\
\hline \multirow[t]{2}{*}{$\mathrm{AO}(\mathrm{mm})$} & Treatment & $0.66 \pm 0.047$ & $0.6 \pm 0.12$ & $0.62 \pm 0.09$ & $0.61 \pm 0.11$ & $0.57 \pm 0.05$ & $0.67 \pm 0.03$ & $0.65 \pm 0.02$ \\
\hline & Control & $0.67 \pm 0.06$ & $0.61 \pm 0.09$ & $0.59 \pm 0.13$ & $0.62 \pm 0.16$ & $0.59 \pm 0.13$ & $\# 0.6 \pm 0.17$ & $\# 0.58 \pm 0.11$ \\
\hline \multirow[t]{2}{*}{ LA (mm) } & Treatment & $0.83 \pm 0.1$ & $0.76 \pm 0.07$ & $0.81 \pm 0.16$ & $0.85 \pm 0.1$ & $0.77 \pm 0.19$ & $0.81 \pm 0.14$ & $0.89 \pm 0.07$ \\
\hline & Control & $0.84 \pm 0.17$ & $0.77 \pm 0.02$ & $0.76 \pm 0.08$ & $0.88 \pm 0.02$ & $0.79 \pm 0.11$ & $0.79 \pm 0.06$ & $\# 0.73 \pm 0.27$ \\
\hline \multirow[t]{2}{*}{ LA/AO } & Treatment & $1.25 \pm 0.15$ & $1.32 \pm 0.36$ & $1.34 \pm 0.35$ & $1.42 \pm 0.18$ & $1.36 \pm 0.37$ & $1.19 \pm 0.2$ & $1.36 \pm 0.05$ \\
\hline & Control & $1.28 \pm 0.34$ & $1.28 \pm 0.2$ & $1.3 \pm 0.24$ & $1.48 \pm 0.42$ & $1.41 \pm 0.52$ & $1.43 \pm 0.6$ & $1.32 \pm 0.62$ \\
\hline \multirow[t]{2}{*}{ LVOT $_{\text {max }}(\mathrm{cm} / \mathrm{s})$} & Treatment & $0.57 \pm 0.1$ & $0.58 \pm 0.14$ & $0.5 \pm 0.12$ & $0.51 \pm 0.07$ & $0.63 \pm 0.08$ & $0.58 \pm 0.12$ & $0.56 \pm 0.02$ \\
\hline & Control & $0.57 \pm 0.13$ & $0.6 \pm 0.08$ & $0.62 \pm 0.075$ & $0.61 \pm 0.09$ & $0.59 \pm 0.03$ & $0.56 \pm 0.07$ & $\# 0.51 \pm 0.14$ \\
\hline \multirow[t]{2}{*}{ RVOT $_{V \max }(\mathrm{cm} / \mathrm{s})$} & Treatment & $0.63 \pm 0.08$ & $0.66 \pm 0.08$ & $0.58 \pm 0.07$ & $0.64 \pm 0.14$ & $0.62 \pm 0.11$ & $0.62 \pm 0.1$ & $0.63 \pm 0.09$ \\
\hline & Control & $0.57 \pm 0.08$ & $0.63 \pm 0.06$ & $0.64 \pm 0.14$ & $0.62 \pm 0.09$ & $0.61 \pm 0.03$ & $0.59 \pm 0.08$ & $\# 0.54 \pm 0.02$ \\
\hline
\end{tabular}

Abbreviations: EDV End-diastolic volume, EF Ejection fraction, ESV End-systolic volume, FS Fractional shortening, IVSd Interventricular septal end diastole, IVSs Interventricular septal end systole, LVIDd Left ventricular internal dimension diastole, LVIDs Left ventricular internal dimension systole, $L V P W d$ Left ventricular posterior wall end diastole, $L V P W s$ Left ventricular posterior wall end systole, SV Stroke volume, AO Aortic root diameter, LA Left atrium diameter, LVOTVmax Left ventricular outflow tract maximum velocity, $R V O T_{V \max }$ Right ventricular outflow tract maximum velocity Data of rabbits are presented as mean \pm SD in the treatment (acute respiratory distress syndrome [ARDS] + bone marrow mesenchymal stem cells) and control (ARDS + PBS) groups at the different time points of sampling $\# p<0.05$; significant compared with the treatment group at the same time

The anti-inflammatory role of MSCs may vary in humans and animals, but the useful effects of MSCs have been shown in several animal models [27] and indicate the significant role of identification feature of MSCs [22]. LPS of gram-negative bacterial wall binds to the CD14/TLR4/MD2 receptor complex, activating pathway and transcription of some inflammation- and apoptosis-related genes and activating innate immune response $[18,25]$ that produces the acute phase of ARDS. Therefore, the LPS-induced animal models could be suitable for cell therapy. In prior findings, only a few animal models have been used to investigate the mechanism of MSC therapy in ARDS, most of which used rat and mouse [25, 28-31]. Although 

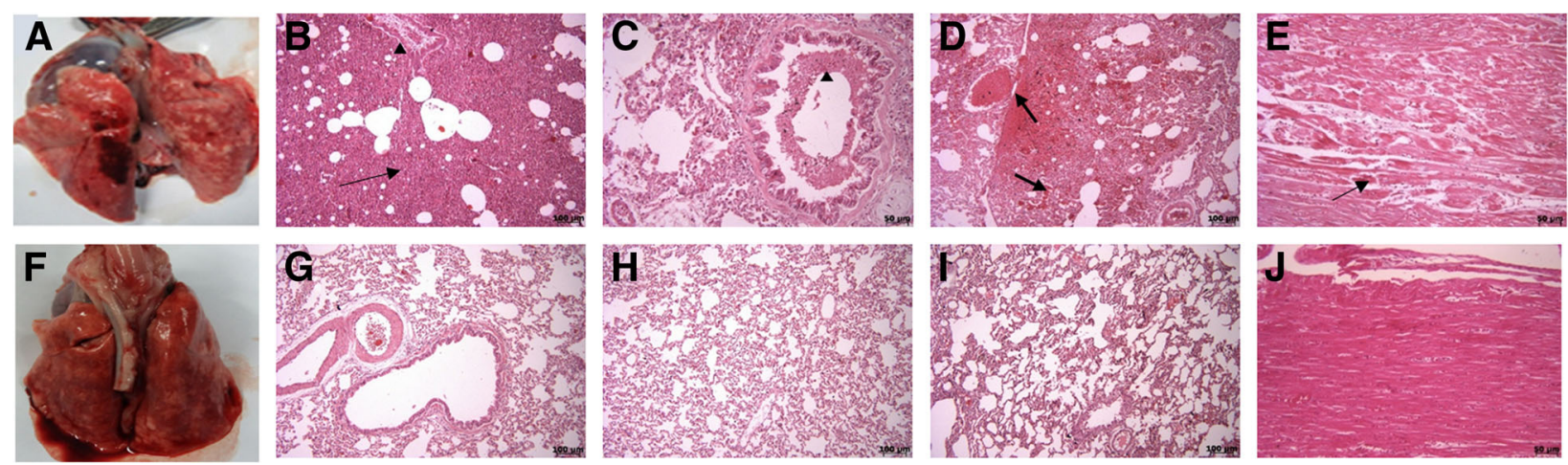

Fig. 8 Necropsy and histopathological findings in the rabbit. a-e Control group. a Macroscopic examination of the lung shows hyperemia, hemorrhage, and edema. b Interstitial edema and pneumonia (arrow). $\mathbf{b}$ and $\mathbf{c}$ Inflammatory cell infiltration (arrowhead). $\mathbf{d}$ Hyperemia and severe hemorrhage in alveoli and parenchyma (arrows). e Myofibrils necrosis of heart (arrow). $\mathbf{f}-\mathbf{k}$ Treatment group. $\mathbf{f}$ Macroscopic examination of the lung shows brief hyperemia and edema. $\mathbf{g}-\mathbf{i}$ Histopathological examination reveals a decrease in damage in the alveoli and parenchyma of the lung. $\mathbf{k}$ Lack of damage to the heart. Note: In all of the tables, data were presented as mean $\pm \mathrm{SD}\left(n=5\right.$ rabbit per group). ${ }^{*} p<0.05$ significant compared with inflammation time in the same group. $\# p<0.05$ significant compared with the control group at the same time

animal models cannot show all complications of human ARDS, a rabbit can display important physiological and pathological features of human ARDS and can be useful for novel therapeutic strategies [18]. As previously described in this study, we used LPS from E. coli strain O55:B5to induce an experimental model of ARDS in the rabbit.

Our results displayed inflammatory cells downregulated by BM-MSCs, which can improve the function of the alveolar-capillary membrane, in agreement with the results of Xiang et al. on improving pulmonary microvascular permeability with MSCs [32]. The reduction of heterophils, macrophages, and the number of total cells were observed in the treated group, unlike the results of other research [26]. The complete blood count findings indicated that despite intrapulmonary administration of LPS and MSCs, there is a relationship between the numbers of intravascular and intra-alveolar heterophils and lymphocytes. Direct administration of LPS effects on gas exchange process and induces acute hypoxemia [33]. The results of studies suggest that MSC transplant can improve hypoxemia via reducing alveolar-arterial oxygen gradient $[29,30]$ which is in agreement with the present study. But the research results of Moodley et al., (2016) conflicted with this study [27]. The difference in injury model and type of cell therapy may be the cause of the variable results. There are not any studies that have reported clinical signs, including HR, RR, and RT, after stromal cell therapy; this study is the first report in which clinical signs were evaluated using a previously described scoring system.

The protective effects of BM-MSCs on ARDS are a result of the immune regulation function and inhibitory $\mathrm{T}$-cell function [31]. Monocytes and macrophages can release inflammatory factors such as TNF- $\alpha$ that play a role in phagocytes of the necrotic and apoptotic cells [34]. Because MSC soluble factors may be the therapeutic basis of MSCs, this result is confirmed by recent reports that demonstrated immunomodulatory properties of MSCs [26]. MSCs' effects are explained by a shift from a proinflammatory to an anti-inflammatory response [26]. Reduced cytokines of proinflammatory (TNF- $\alpha$ and IL-6) and increased cytokines of anti-inflammatory (IL-10) in BAL and plasma samples play principal roles in the treatment mechanism of ARDS [26, $29,30]$. In the present study, the TNF- $\alpha$ concentration decreased following MSC therapy, which is similar to many studies [31]. The IL-10 level increased after the use of MSCs and inhibited antigen-presenting cell function and inflammation and enhanced tolerance, but our findings are not similar to some other studies [26, 30]. Beneficial effects of MSCs may be mediated by a decrease of TNF that indicated the attenuation of the inflammation [26]. Prostaglandin E2 (PGE2) has a critical role in IL-10 and IL-6 secretion from macrophages [31]. It is possible that TNF- and IL-6-dependent PGE2 production plays a major role as a clinical sign and in particular hyperthermia in the acute phase of inflammation [34]. TNF has roles in local inflammation complications such as leukocyte stimulation (neutrophils and macrophage) in BAL and lung endothelium that was shown in the pathology. Also, TNF has roles in systemic complications such as hyperthermia, C-reactive protein, leukocytosis, necrosis, and apoptosis, decreasing appetite, and even decreases of cardiac output and vascular permeability and increases in edema and hypotension.

In this study, CT scans and echocardiography were used to follow improvement and management of ARDS during BM-MSC therapy. One particular feature of ARDS is lack of aerated lung volume caused by inflammation and edema, and total lung volume reduction (air 
+ parenchyma) mostly in the lower lobes can explain hypoxemia, low respiratory compliance, and alveolar dead space and increased pulmonary vascular permeability [35, 36]. CT scanning is a common clinical diagnostic tool, a specific, repeatable, and noninvasive technique for diagnosis that until now has rarely been used as a research tool, and there is not any valid data of the distribution region of the existence or absence of air in alveolus during ARDS and especially after cell-based therapy. Our findings based on CT scanning are matched with the diagnosis of pathology and all the other outcomes. Therefore, it can be said that CT scanning is a suitable method for evaluation of the stromal cell therapy effects in pulmonary inflammation and edema, but further studies are needed in this field. Interactions between lung, right ventricle, and pulmonary circulation are critical in ARDS. Serial echocardiographic measurements have a potential clinical diagnosis in the early stage ARDS as a prognostic and therapeutic method. We showed that ARDS causes changes in echocardiographic parameters and reduces cardiac function, whereas transplant of BM-MSCs was able to prevent these changes.

We demonstrated that MSCs could attenuate the inflammation by reducing pathological lung changes [31], but in some research, no significant data were reported regarding pathology. This variation may be caused by short study duration so that further studies are needed. Our histopathological examination, like other findings from imaging and all of the laboratory results, showed that BM-MSC transplant could improve ARDS.

\section{Conclusions}

Many studies on cell-based therapies in ARDS have been done, but most of them focused on molecular and signal tests. Although these studies could clear pathways, they are still far from tissue function. In this study, we tried to explain the MSCs' effects on organ function. We investigated effects of BM-MSCs in an experimental model of ARDS and confirmed that MSCs decrease inflammation and improve alveolar fluid clearance and have a protective role in ARDS. Improvement in clinical signs, the decrease of inflammatory cells in blood and BAL, the balance in blood gases and cytokines, the decrease in the Hounsfield units, no changes in echocardiographic parameters. and the reduction of pulmonary hemorrhage and edema in pathology were observed. Despite these results, subsequent studies are required to confirm the decrease in inflammation, and physiological parameters over the long term and many experiments should be performed until stromal cell therapy is validated as a method of routine clinical treatment.

\section{Additional file}

Additional file 1: Additional methods, Figures S1-S6 and Tables S1-S7. (DOCX $1420 \mathrm{~kb})$

\section{Abbreviations}

ABG: Arterial blood gases; ALI: Acute lung injury; AnGap: Anion gap; AO: Aortic root diameter; ARDS: Acute respiratory distress syndrome; BAL: Bronchoalveolar lavage; BM: Bone marrow; BM-MSCs: Bone marrow mesenchymal stem cells; CD14: Cluster of differentiation 14; CT: Computed tomography; 'EDV: End-diastolic volume; EF: Ejection fraction; ESV: End-systolic volume; FS: Fractional shortening; GMP: Good manufacturing practice; $\mathrm{HCO}_{3}$ : Bicarbonate; Hct: Hematocrit; Hgb: Whole-blood hemoglobin concentration; HR: Heart rate; IVSd: Interventricular septal end diastole; IVSs: Interventricular septal end systole; LA: Left atrium diameter; LPS: Lipopolysaccharide; LVID: Left ventricular internal dimension; LVOT Vmax: Left ventricular outflow tract maximum velocity;

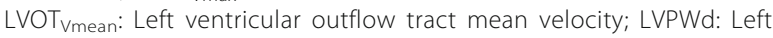
ventricular posterior wall end diastole; LVPWs: Left ventricular posterior wall end systole; MCHC: Mean erythrocyte hemoglobin concentration; MSCs: Mesenchymal stem cells; $\mathrm{PCO}_{2}$ : Partial pressure of carbon dioxide; PCV: Packed cell volume; Plt: Platelets; $\mathrm{PO}_{2}$ : Partial pressure of oxygen; RBC: Red blood cell; RR: Respiratory rate; RT: Room temperature; RVOT Vmax: Right ventricular outflow tract maximum velocity; RVOT Vmean: Right ventricular outflow tract mean velocity; $\mathrm{SatO}_{2}: \mathrm{O}_{2}$ saturation; $\mathrm{SV}$ : Stroke volume; $\mathrm{TCO}_{2}$ : Total $\mathrm{CO}_{2}$; TLR4: Toll-like receptor 4; TNF-a: Tumor necrosis factor-a; WBC: White blood cell

\section{Acknowledgements}

Not applicable.

\section{Funding}

No funding was received for this study.

\section{Availability of data and materials}

The authors want to share their data.

\begin{abstract}
Authors' contributions
MRMD designed the study, commented on the data analysis, and revised and finalized the manuscript. MJF performed the cellular and clinical experiments and the molecular studies and prepared the initial manuscript. SSC designed the study, performed the cellular experiments, prepared the initial manuscript, and revised and finalized the manuscript. MMD analyzed and interpreted the data and finalized the manuscript. AV performed the clinical experiments and commented on the data analysis. RM performed the clinical experiments. All authors read and approved the final manuscript.
\end{abstract}

Ethics approval and consent to participate

All experimental protocols and animal protocols were reviewed and approved by the Animal Research Ethical Committee of the University of Tehran (Tehran, Iran).

Consent for publication

Not applicable.

Competing interests

The authors declare that they have no competing interests.

\section{Publisher's Note}

Springer Nature remains neutral with regard to jurisdictional claims in published maps and institutional affiliations.

\section{Author details}

'Department of Internal Medicine, Faculty of Veterinary Medicine, University of Tehran, Tehran, Iran. ${ }^{2}$ Department of Surgery and Radiology, Faculty of Veterinary Medicine, University of Tehran, Tehran, Iran. ${ }^{3}$ Institute of Biomedical Research, University of Tehran, Tehran, Iran. 
Received: 27 June 2018 Accepted: 21 November 2018

Published online: 20 December 2018

\section{References}

1. ARDS Definition Task Force, Ranieri VM, Rubenfeld GD, Thompson BT, Ferguson ND, Caldwell E, Fan E, Camporota L, Slutsky AS. Acute respiratory distress syndrome: the Berlin Definition. JAMA. 2012;307(23):2526-33.

2. Bernard GR, Artigas A. The definition of ARDS revisited: 20 years later. Intensive Care Med. 2016:42(5):640-2.

3. Gonzales JN, Lucas R, Verin AD. The acute respiratory distress syndrome: mechanisms and perspective therapeutic approaches. Austin J Vasc Med. 2015;2(1):1009

4. Matthay MA, Zemans RL. The acute respiratory distress syndrome: pathogenesis and treatment. Annu Rev Pathol. 2011;6:147-63.

5. Cruz FF, Weiss DJ, Rocco PR. Prospects and progress in cell therapy for acute respiratory distress syndrome. Expert Opin Biol Ther. 2016;16(11): 1353-60.

6. Dushianthan A, Grocott MPW, Postle AD, Cusack R. Acute respiratory distress syndrome and acute lung injury. Postgrad Med J. 2011;87(1031):612-22.

7. Mclntyre LA, Moher D, Fergusson DA, Sullivan KJ, Mei SH, Lalu M, Marshall J, McLeod M, Griffin G, Grimshaw J, et al. Efficacy of mesenchymal stromal cell therapy for acute lung injury in preclinical animal models: a systematic review. PLoS One. 2016;11(1):e0147170.

8. Bein T, Grasso S, Moerer O, Quintel M, Guerin C, Deja M, Brondani A, Mehta S. The standard of care of patients with ARDS: ventilatory settings and rescue therapies for refractory hypoxemia. Intensive Care Med. 2016;42(5): 699-711.

9. Abbasi J, Mokhber Dezfouli MR, Sadeghian Chaleshtori S, Dehghan MM, Vajhi A, Baharvand H, Ghanei M, Jabari Fakhr M. Improvement of clinical signs in experimental model of acute respiratory distress syndrome (ARDS) in sheep following autograft of bone marrow-derived mesenchymal stem cells (BM-MSCs). J Vet Res. 2018;73:17-26.

10. Mokhber Dezfouli MR, Sadeghian Chaleshtori S, Moradmand A, Basiri M, Baharvand H, Tahamtani Y. Hydrocortisone promotes differentiation of mouse embryonic stem cell-derived definitive endoderm toward lung alveolar epithelial cells. Cell J. 2019;20(4):469-76.

11. Dezfouli MR, Chaleshtori SS, Dehghan MM, Tavanaeimanesh H, Baharvand $\mathrm{H}$, Tahamtani Y. The therapeutic potential of differentiated lung cells from embryonic stem cells in lung diseases. Curr Stem Cell Res Ther. 2017;12(1): 80-4.

12. Sadeghian Chaleshtori S, Dezfouli MR, Dehghan MM, Tavanaeimanesh H. Generation of lung and airway epithelial cells from embryonic stem cells in vitro. Crit Rev Eukaryot Gene Expr. 2016;26(1):1-9.

13. Matthay MA. Therapeutic potential of mesenchymal stromal cells for acute respiratory distress syndrome. Ann Am Thorac Soc. 2015;12(Suppl 1):S54-7.

14. Sdrimas K, Kourembanas S. MSC microvesicles for the treatment of lung disease: a new paradigm for cell-free therapy. Antioxid Redox Signal. 2014; 21(13):1905-15.

15. Goolaerts A, Pellan-Randrianarison N, Larghero J, Vanneaux V, Uzunhan Y, Gille T, Dard N, Planès C, Matthay MA, Clerici C. Conditioned media from mesenchymal stromal cells restore sodium transport and preserve epithelial permeability in an in vitro model of acute alveolar injury. Am J Physiol Lung Cell Mol Physiol. 2014;306(11):L975-85.

16. Slutsky AS, Villar J, Pesenti A. Happy 50th birthday ARDS! Intensive Care Med. 2016;42(5):637-9.

17. Kamaruzaman NA, Kardia E, Kamaldin N', Latahir AZ, Yahaya BH. The rabbit as a model for studying lung disease and stem cell therapy. Biomed Res Int. 2013;2013:691830.

18. Mei SH, Dos Santos CC, Stewart DJ. Advances in stem cell and cell-based gene therapy approaches for experimental acute lung injury: a review of preclinical studies. Hum Gene Ther. 2016;27(10):802-12.

19. Gao X, Chen W, Liang Z, Chen L. Autotransplantation of circulating endothelial progenitor cells protects against lipopolysaccharide-induced acute lung injury in rabbit. Int Immunopharmacol. 2011;11(10):1584-90.

20. Zhu F, Guo GH, Chen W, Peng Y, Xing JJ, Wang NY. Effect of bone marrowderived mesenchymal stem cells transplantation on the inflammatory response and lung injury in rabbit with inhalation injury [in Chinese]. Zhonghua Shao Shang Za Zhi. 2010;26(5):360-5.

21. Fang X, Abbott J, Cheng L, Colby JK, Lee JW, Levy BD, Matthay MA. Human mesenchymal stem (stromal) cells promote the resolution of acute lung injury in part through lipoxin A4. J Immunol. 2015;195(3):875-81.
22. Kavanagh DP, Robinson J, Kalia N. Mesenchymal stem cell priming: finetuning adhesion and function. Stem Cell Rev. 2014;10(4):587-99.

23. Loebinger MR, Aguilar S, Janes SM. Therapeutic potential of stem cells in lung disease: progress and pitfalls. Clin Sci (Lond). 2008;114(2):99-108.

24. Burnham EL, Janssen WJ, Riches DW, Moss M, Downey GP. The fibroproliferative response in acute respiratory distress syndrome: mechanisms and clinical significance. Eur Respir J. 2014;43(1):276-85.

25. Zhu H, Xiong Y, Xia Y, Zhang R, Tian D, Wang T, Dai J, Wang L, Yao H, Jiang $H$, et al. Therapeutic effects of human umbilical cord-derived mesenchymal stem cells in acute lung injury mice. Sci Rep. 2017;7:39889.

26. Gupta N, Su X, Popov B, Lee JW, Serikov V, Matthay MA. Intrapulmonary delivery of bone marrow-derived mesenchymal stem cells improves survival and attenuates endotoxin-induced acute lung injury in mice. J Immunol. 2007;179(3):1855-63.

27. Moodley Y, Sturm M, Shaw K, Shimbori C, Tan DBA, Kolb M, Graham R. Human mesenchymal stem cells attenuate early damage in a ventilated pig model of acute lung injury. Stem Cell Res. 2016;17(1):25-31.

28. Monsel A, Zhu YG, Gennai S, Hao Q, Hu S, Rouby JJ, Rosenzwajg M, Matthay MA, Lee JW. Therapeutic effects of human mesenchymal stem cell-derived microvesicles in severe pneumonia in mice. Am J Respir Crit Care Med. 2015;192(3):324-36.

29. Li Y, Xu J, Shi W, Chen C, Shao Y, Zhu L, Lu W, Han X. Mesenchymal stromal cell treatment prevents H9N2 avian influenza virus-induced acute lung injury in mice. Stem Cell Res Ther. 2016;7:159.

30. Devaney J, Horie S, Masterson C, Elliman S, Barry F, O'Brien T, Curley GF, OToole D, Laffey JG. Human mesenchymal stromal cells decrease the severity of acute lung injury induced by E. coli in the rat. Thorax. 2015;70(7): $625-35$

31. Zhou J, Jiang L, Long X, Fu C, Wang X, Wu X, Liu Z, Zhu F, Shi J, Li S. Bonemarrow-derived mesenchymal stem cells inhibit gastric aspiration lung injury and inflammation in rats. J Cell Mol Med. 2016;20(9):1706-17.

32. Xiang $B$, Chen $L$, Wang $X$, Zhao $Y$, Wang $Y$, Xiang $C$. Transplantation of menstrual blood-derived mesenchymal stem cells promotes the repair of LPS-induced acute lung injury. Int J Mol Sci. 2017;18(4):E689.

33. Pedrazza L, Cunha AA, Luft C, Nunes NK, Schimitz F, Gassen RB, Breda RV, Donadio MVF, de Souza Wyse AT, Pitrez PMC, Rosa JL, de Oliveira JR. Mesenchymal stem cells improves survival in LPS-induced acute lung injury acting through inhibition of NETs formation. J Cell Physiol. 2017;232(12): 3552-64.

34. Shi Y, Su J, Roberts Al, Shou P, Rabson AB, Ren G. How mesenchymal stem cells interact with tissue immune responses. Trends Immunol. 2012;33(3):136-43

35. Caironi P, Carlesso E, Gattinoni L. Radiological imaging in acute lung injury and acute respiratory distress syndrome. Semin Respir Crit Care Med. 2006; 27(4):404-15.

36. Gattinoni L, Caironi P, Valenza F, Carlesso E. The role of CT-scan studies for the diagnosis and therapy of acute respiratory distress syndrome. Clin Chest Med. 2006;27(4):559-70.

Ready to submit your research? Choose BMC and benefit from:

- fast, convenient online submission

- thorough peer review by experienced researchers in your field

- rapid publication on acceptance

- support for research data, including large and complex data types

- gold Open Access which fosters wider collaboration and increased citations

- maximum visibility for your research: over $100 \mathrm{M}$ website views per year

At $\mathrm{BMC}$, research is always in progress.

Learn more biomedcentral.com/submissions 